\title{
THE POSS-ABILITY PRINCIPLE, G-CASES, AND FITCH PROPOSITIONS
}

\author{
Noah GORDON
}

\begin{abstract}
There is a very plausible principle linking abilities and possibilities: If $\mathrm{S}$ is able to $\Phi$, then it is metaphysically possible that S $\Phi$ 's. Jack Spencer recently proposed a class of counterexamples to this principle involving the ability to know certain propositions. I renew an argument against these counterexamples based on the unknowability of Fitch propositions. In doing so, I provide a new argument for the unknowability of Fitch propositions and show that Spencer's counterexamples are in tension with a principle weaker than the one linking abilities and possibilities.
\end{abstract}

KEYWORDS: Poss-Ability, Fitch propositions, G-cases, abilities, knowability

Here's a highly intuitive principle linking abilities and possibilities:

Poss-Ability: (For all $S$ and all $\Phi$ ) If $S$ is able to $\Phi$, then it is metaphysically possible that $\mathrm{S} \Phi$ 's.

In addition to being intuitive, Poss-Ability underwrites much contemporary theorizing about abilities. For example, it is a consequence of both of the leading metaphysical analyses of abilities, ${ }^{1}$ and it mediates the connection between 'ought' and the 'can' of metaphysical possibility. ${ }^{2}$

Much hangs, then, on the truth of Poss-Ability. In this note, I argue against Jack Spencer's class of counterexamples to Poss-Ability by drawing on considerations from epistemic logic to renew an argument against these counterexamples based on the unknowability of Fitch propositions. ${ }^{3}$

Spencer's class of counterexamples centers around the following case: ${ }^{4}$

Simple G: Consider a fully deterministic world w. ${ }^{5}$ Let ' $H$ ' name the complete

${ }^{1}$ See 481-483 within Jack Spencer, “Able to Do the Impossible,” Mind 126, 502 (2017):466-497.

2 Spencer, "Able to Do the Impossible," 486-488.

${ }^{3}$ For other arguments against the G-cases, see Anthony Nguyen, "Unable to Do the Impossible," Mind 129, 514 (2020): 585-602.

${ }^{4}$ Spencer, "Able to Do the Impossible," 468.

${ }^{5} \mathrm{~A}$ world $\mathrm{w}$ is deterministic just in case a complete specification of the laws of $\mathrm{w}$ and the state of $\mathrm{w}$ at any time entails a complete specification of the state of $\mathrm{w}$ at any other time. See Carl Hoefer "Causal Determinism," The Stanford Encyclopedia of Philosophy (2016) for a similar definition of 'determinism.'

(C) LOGOS \& EPISTEME, XII, 1 (2021): 117-125 
Noah Gordon

specification of the initial conditions of $w$ and ' $L$ ' name the complete specification of the laws of nature of $w$. Suppose that $\mathrm{H} \wedge \mathrm{L}$ is common knowledge in G's community; it is taught in high school physics classes. $\mathrm{G}$ is one the top students in her class and is excellent in physics as well. However, for one accidental reason or another $\mathrm{G}$ misses the class in which her teacher covers the laws and initial conditions and so never comes to believe $\mathrm{H} \wedge \mathrm{L}$ or know $\mathrm{H} \wedge \mathrm{L}$, though many of her classmates do.

Spencer judges that in Simple $G, G$ is able to know $H \wedge$ L. This quickly leads to the falsity of Poss-Ability, since it is metaphysically impossible that G knows $\mathrm{H} \wedge \mathrm{L}^{6}{ }^{6}$ Simple $G$ serves as something of a template for generating counterexamples to PossAbility. For example, in Gettier G, G truly believes $\mathrm{H} \wedge \mathrm{L}$ but fails to know $\mathrm{H} \wedge \mathrm{L}$ for Gettier-like reasons. ${ }^{7}$ Following Spencer, I call cases like these G-cases. ${ }^{8}$

There is an argument from the unknowability of Fitch propositions against the G-cases. ${ }^{9}$ Letting ' $K_{G} \Phi$ ' regiment the claim ' $G$ knows that $\Phi$,' Fitch propositions are of the form ' $\Phi \wedge \neg K_{\mathrm{G}} \Phi$.' The unknowability of Fitch propositions is the thesis that no one is able to know a Fitch proposition. In other words, it is the claim that:

Unknowability of Fitch propositions: $\forall S \forall \Phi(\mathrm{S}$ is not able to know that $\Phi \wedge \neg \mathrm{Ks} \Phi)$.

Spencer considers the following argument from the unknowability of Fitch propositions to the claim that $\mathrm{G}$ is not able to know $\mathrm{H} \wedge \mathrm{L}$ : Suppose that $\mathrm{G}$ is able to know $\mathrm{H} \wedge \mathrm{L}$. $\mathrm{H} \wedge \mathrm{L}$ entails $\neg \mathrm{KG}_{\mathrm{G}}(\mathrm{H} \wedge \mathrm{L})$. Now if knowability for $\mathrm{G}$ is closed under entailment, then $\mathrm{G}$ is able to know that $\neg \mathrm{K}_{\mathrm{G}}(\mathrm{H} \wedge \mathrm{L})$. If knowability for $\mathrm{G}$ is further closed under conjunction, it follows that $\mathrm{G}$ is able to know $(\mathrm{H} \wedge \mathrm{L}) \wedge\left(\neg \mathrm{K}_{\mathrm{G}}(\mathrm{H} \wedge \mathrm{L})\right.$. But this is a Fitch proposition. It follows from the unknowability of Fitch propositions that our assumption is false, so $\mathrm{G}$ is not able to know $\mathrm{H} \wedge \mathrm{L}$.

I agree with Spencer that this argument is no good. The problem is that there is no reason to think that knowability for $G$ is closed under entailment or conjunction. There are many ordinary agents for whom it is not plausible that they are able to know every consequence of anything they know. Moreover Spencer

\footnotetext{
${ }^{6}$ If $\mathrm{H} \wedge \mathrm{L}$ is false, then $\mathrm{G}$ does not know $\mathrm{H} \wedge \mathrm{L}$, since knowledge requires truth. But if $\mathrm{H} \wedge \mathrm{L}$ is true, then $\mathrm{G}$ does not know $\mathrm{H} \wedge \mathrm{L}$, since $\mathrm{H} \wedge \mathrm{L}$ entails that $\mathrm{G}$ does not come to know $\mathrm{H} \wedge \mathrm{L}$. C.f. Spencer, "Able to Do the Impossible." 469 and 490.

${ }^{7}$ Spencer, "Able to Do the Impossible," 477-478.

${ }^{8}$ In this note, I restrict my attention to G-cases involving the ability to know. Spencer does discuss some counterexamples to Poss-Ability that do not involve the ability to know. For discussion of these, see Nguyen, "Unable to do the Impossible," section 4.

${ }^{9}$ Spencer, "Able to Do the Impossible," 489-491.
} 
argues that if Fitch propositions are unknowable, then knowability is not closed under either conjunction or known entailment. ${ }^{10}$

However, there is an improved version of the objection which circumvents these problems. The crucial point is that the properties of knowability may differ when the abilities of different agents are in question. While knowability in general is not closed under entailment or conjunction, there is still a limited class of agents for whom their ability to know is closed under entailment and conjunction. In particular, consider the class of idealized agents who are both metaphysically omniscient and have perfect introspective access to their own epistemic states. A metaphysically omniscient agent $\mathrm{C}$ is such that:

Whenever $\mathrm{C}$ knows all of the formulas in a set $\Gamma$ (including the empty set) and A

follows logically/metaphysically from $\Gamma$, then $\mathrm{C}$ also knows $\mathrm{A} .{ }^{11}$

Metaphysical omniscience guarantees that knowability is closed under logical and metaphysical entailment. Perfect introspection (for an agent S) is characterized by at least the following principles:

KK Principle: $\mathrm{Ks}_{\mathrm{s}} \rightarrow \mathrm{KsKs} \Phi$

Consistent Introspection: $\mathrm{Bs}_{\mathrm{s}} \neg \mathrm{Bs} \Phi \rightarrow \neg \mathrm{Bs} \Phi .{ }^{12}$

Given metaphysical omniscience, whenever S knows $\Phi$ and $\Phi$ entails $\Psi$, S knows $\Psi$. Given the KK principle, if $S$ knows $\Phi$ and $S$ knows $\Psi$, then $S$ knows that $S$ knows both of these. Thus if $S$ is able to know $\Phi$ and $\Phi$ entails $\Psi, S$ is in a position to know $\Phi \wedge \Psi$. So the relevant kind of closure invoked by the argument against $\mathrm{G}$-cases does hold for this class of idealized agents.

The new and improved version of the argument then says that if an idealized version of $G$, namely $G+$, for whom the above conditions held were able to know $\mathrm{H}$ $\wedge \mathrm{L}$, then they would be able to know a Fitch proposition, namely $(\mathrm{H} \wedge \mathrm{L}) \wedge(\neg$ $\left.\mathrm{K}_{\mathrm{G}}(\mathrm{H} \wedge \mathrm{L})\right)$. But since no one is able to know a Fitch proposition, $\mathrm{G}+$ is not able to know $\mathrm{H} \wedge \mathrm{L}$. The final step of the argument is simply the claim that if a highly

${ }^{10}$ Spencer, "Able to Do the Impossible," 490-491.

${ }^{11}$ This definition appears in Rendsvig and Symons, "Epistemic Logic," The Stanford Encyclopedia of Philosophy (2019).

${ }^{12}$ Consistent Introspection follows from the belief analogue of the KK principle plus a weak principle on rational belief:

(1) $\mathrm{B}_{\mathrm{G}} \Phi \rightarrow \mathrm{BG}_{\mathrm{G}} \mathrm{B}_{\mathrm{G}} \Phi$

(BB Principle)

(2) $\mathrm{B}_{\mathrm{G}} \mathrm{B}_{\mathrm{G}} \Phi \rightarrow \sim \mathrm{B}_{\mathrm{G}} \sim \mathrm{B}_{\mathrm{G}} \Phi$

(Weak Rational Belief)

(3) $\mathrm{B}_{\mathrm{G}} \Phi \rightarrow \sim \mathrm{B}_{\mathrm{G}} \sim \mathrm{B}_{\mathrm{G}} \Phi$

$(1,2, \mathrm{PL})$

(4) $\mathrm{B}_{\mathrm{G}} \sim \mathrm{BG}_{\mathrm{G}} \Phi \rightarrow \sim \mathrm{BG}_{\mathrm{G}} \Phi$

$(3, \mathrm{PL})$ 


\title{
Noah Gordon
}

idealized version of $G$ would be unable to know $H \wedge L$, then plain old $G$ is not able to know $\mathrm{H} \wedge \mathrm{L}$ simply for failure to satisfy the relevant closure conditions.

Against this improved version of the Fitch objection, several of Spencer's responses simply fall flat. First, I already mentioned that Spencer argues that if Fitch propositions are unknowable, then knowability is not closed under either conjunction or known entailment. But the relevant question is, knowability for whom? Both of Spencer's counterexamples here are for agents who lack knowledge of certain mathematical truths. ${ }^{13}$ Assuming that mathematical truths are metaphysically necessary, these agents fail to be metaphysically omniscient. Therefore, these counterexamples cannot show that knowability is not closed under conjunction or entailment for the relevant idealized kind of agent.

Second, Spencer objects that:

\begin{abstract}
Although $\neg \mathrm{K}(\mathrm{H} \wedge \mathrm{L})$ may be necessitated by $\mathrm{H} \wedge \mathrm{L}$, it need not be scrutable on the basis of $\mathrm{H} \wedge \mathrm{L}$, so there is no reason to think that $\mathrm{G}$ (or $\mathrm{G}+$ ) ought to be able to know that $\mathrm{\theta}(\mathrm{H} \wedge \mathrm{L} \rightarrow \neg \mathrm{K}(\mathrm{H} \wedge \mathrm{L}))$. Thus, even if the threatening argument is sound which I doubt very much - there would still be some G-cases that did not lead to the knowability of Fitch propositions, and so the main claims of this paper would stand. ${ }^{14}$
\end{abstract}

But I respond that if $\mathrm{G}+$ is metaphysically omniscient, then there is eminently good reason to think that $\mathrm{G}+$ ought to be able to know that ? $\left(\mathrm{H} \wedge \mathrm{L} \rightarrow \neg \mathrm{K}_{\mathrm{G}}(\mathrm{H} \wedge \mathrm{L})\right)$, since metaphysically omniscient agents know every metaphysically necessary truth. The second part of the quoted passage seems to suggest that even if the fact that $H \wedge L$ entails $\neg \mathrm{KG}_{\mathrm{G}}(\mathrm{H} \wedge \mathrm{L})$ is knowable for some $\mathrm{G}$ in some $\mathrm{G}$ case, say for metaphysically omniscient $\mathrm{G}+$, we still might maintain that there are some $\mathrm{G}$-cases which do not lead to knowability of Fitch propositions, particularly where $G$ is not able to know ? $\left(\mathrm{H} \wedge \mathrm{L} \rightarrow \neg \mathrm{K}_{\mathrm{G}}(\mathrm{H} \wedge \mathrm{L})\right)$. But, as I have suggested, this sort of reasoning is perverse. If a metaphysically omniscient version of $G$ is not able to know $H \wedge L$, surely $G$ is not able to know $\mathrm{H} \wedge \mathrm{L}$ merely out of ignorance of the metaphysical truth that $\mathrm{H} \wedge$ L entails $\neg \mathrm{KG}_{\mathrm{G}}(\mathrm{H} \wedge \mathrm{L})$.

Spencer's third response to objections based on the unknowability of Fitch propositions is the most interesting. He proposes to bite the bullet on the knowability of Fitch propositions, since the main argument for their unknowability depends on Poss-Ability. There is a simple proof that it is not metaphysically possible to know a Fitch proposition, first reported by Frederich Fitch. ${ }^{15}$ The proof

\footnotetext{
${ }^{13}$ Spencer, "Able to Do the Impossible," fn 43.

${ }^{14}$ Spencer, "Able to Do the Impossible," 490.

${ }^{15}$ Frederich Fitch, "A Logical Analysis of Some Value Concepts," The Journal of Symbolic Logic 28, 2 (1963).
} 
demonstrates that knowledge of a Fitch proposition would require both knowing and not knowing some proposition, which is of course impossible:

(1) ? $(\mathrm{K}(\Phi \wedge \neg \mathrm{K} \Phi) \rightarrow(\mathrm{K} \Phi \wedge \mathrm{K} \neg \mathrm{K} \Phi))$ (Knowledge distributes over conjunction)

(2) $?((\mathrm{~K} \Phi \wedge \mathrm{K} \neg \mathrm{K} \Phi) \rightarrow(\mathrm{K} \Phi \wedge \neg \mathrm{K} \Phi)) \quad$ (Factivity of knowledge)

(3) $?(\mathrm{~K}(\Phi \wedge \neg \mathrm{K} \Phi) \rightarrow(\mathrm{K} \Phi \wedge \neg \mathrm{K} \Phi)) \quad(1,2, \mathrm{PL}, \mathrm{K} \text { axiom })^{16}$

(4) $?\urcorner(\mathrm{K} \Phi \wedge \neg \mathrm{K} \Phi)$

(5) ? $\neg(\mathrm{K}(\Phi \wedge \neg \mathrm{K} \Phi))$

(3, 4, PL, K axiom)

Interpreting '??' as a metaphysical necessity operator, the above result shows that it is metaphysically impossible to know a Fitch proposition, provided agents satisfy the plausible distribution over conjunction condition. What Spencer points out is that to conclude that no one is able to know a Fitch proposition on the basis of this argument depends on an application of Poss-Ability. Spencer could allow that it is metaphysically impossible to know a Fitch proposition, yet resist the claim that they are unknowable in the sense of ability.

Spencer calls for a new argument to be given for the unknowability of Fitch propositions. This seems something of a double standard. No argument is given for the claim that $\mathrm{G}$ is able to know $\mathrm{H} \wedge \mathrm{L}$. If it came down to a clash of intuitions, I would favor the unknowability of Fitch propositions over Spencer's judgment in Gcases. Nonetheless, there is at least one independent argument for the unknowability of Fitch propositions. It relies on a principle weaker than Poss-Ability, namely:

Believe-Ability: If $\mathrm{S}$ is able to know $\Phi$, then it is metaphysically possible for $\mathrm{S}$ to believe $\Phi$.

This principle is highly plausible and nothing in the G-cases prima facie rules it out, since there may be many worlds where $G$ falsely believes $H \wedge L$, and Gettier-G explicitly relies on the construction that $\mathrm{G}$ believes $\mathrm{H} \wedge \mathrm{L}$.

16 'PL' stands for 'propositional logic' and the $\mathrm{K}$ axiom of normal modal logics is as follows:

$\mathrm{K}$ Axiom: $(\Phi \rightarrow \Psi) \rightarrow($ 回 $\Phi \rightarrow$ ? $\Psi)$

Many proofs in this paper appeal to the combination of PL and the $\mathrm{K}$ axiom to make inferences valid in propositional logic within the scope of the metaphysical necessity operator. To see that this is valid, suppose that $\Phi \rightarrow \Psi$ is provable in PL. Since anything provable in PL is metaphysically necessary, $(\Phi \rightarrow \Psi)$ follows. Then by the $\mathrm{K}$ axiom, $(\Phi \rightarrow$ ? $\Psi$ is true. So if we begin with some formula $\Phi$ and $\Phi \rightarrow \Psi$ is provable in PL, we may conclude ? $\Psi$ by applications of PL and the K axiom. Alternatively, to see that this is valid one may simply reflect on the fact that the logical consequences of any metaphysically necessary truth are also metaphysically necessary. 


\section{Noah Gordon}

We can show if Believe-Ability is true, then any agent $\mathrm{S}$ who satisfies a kind of epistemic anti-akrasia constraint is not able to know a Fitch proposition:

Anti-Akrasia: $\mathrm{Bs} \neg \mathrm{Ks} \Phi \rightarrow \neg \mathrm{Bs} \Phi$.

Anti-Akrasia says that if S introspects and comes to believe that they do not know $\Phi$, they will not believe $\Phi$. Just as doing what's best is the aim of action, knowledge is the aim of belief. So as an akratic person $\Psi$ 's whilst believing that $\Psi$-ing is not the best option overall, an epistemically akratic person believes $\Phi$ whilst believing that they do not know $\Phi$. I take Anti-Akrasia to express a plausible principle of perfect rationality.

Anti-Akrasia and Believe-Abilitity together imply the unknowability of Fitch propositions, since believing a Fitch proposition involves believing both $\Phi$ and that you don't know $\Phi$. Letting 'A ${ }_{G} \Phi$ ' regiment the claim that $\mathrm{G}$ is able to bring it about that $\Phi$ :
(1) $?\left(\mathrm{~B}_{\mathrm{G}}\left(\Phi \wedge \neg \mathrm{K}_{\mathrm{G}} \Phi\right) \rightarrow\left(\mathrm{B}_{\mathrm{G}} \Phi \wedge \mathrm{BG}_{\mathrm{G}} \neg \mathrm{K}_{\mathrm{G}} \Phi\right)\right)$
(B $\mathrm{G}_{\mathrm{G}}$ distribution over conjunction)
(2) ๑ $\neg\left(\mathrm{B}_{\mathrm{G}} \Phi \wedge \mathrm{B}_{\mathrm{G}} \neg \mathrm{K}_{\mathrm{G}} \Phi\right)$
(Anti-Akrasia, PL, K axiom)
(3) $? \neg\left(\mathrm{B}_{\mathrm{G}}\left(\Phi \wedge \neg \mathrm{K}_{\mathrm{G}} \Phi\right)\right)$
(1, 2, PL, K axiom)
(4) $\neg \diamond \neg \neg\left(\mathrm{B}_{\mathrm{G}}\left(\Phi \wedge \neg \mathrm{K}_{\mathrm{G}} \Phi\right)\right)$
(3, Duality of $\square$ )
(5) $\neg \diamond\left(\mathrm{B}_{\mathrm{G}}\left(\Phi \wedge \neg \mathrm{K}_{\mathrm{G}} \Phi\right)\right)$
(6) $\mathrm{AG}_{\mathrm{G}} \mathrm{K}_{\mathrm{G}}\left(\Phi \wedge \neg \mathrm{K}_{\mathrm{G}} \Phi\right) \rightarrow \diamond \mathrm{B}_{\mathrm{G}}\left(\Phi \wedge \neg \mathrm{K}_{\mathrm{G}} \Phi\right)$
(Believe-Ability)
(7) $\neg \mathrm{A}_{\mathrm{G}} \mathrm{K}_{\mathrm{G}}\left(\Phi \wedge \neg \mathrm{K}_{\mathrm{G}} \Phi\right)$

The above proof shows that given Believe-Ability, no agent satisfying distribution of belief over conjunction and Anti-Akrasia is able to know a Fitch proposition. A metaphysically omniscient agent satisfies the distribution constraint, and a perfectly rational agent satisfies Anti-Akrasia. Therefore, no metaphysically omniscient and perfectly rational agent is able to know a Fitch proposition. ${ }^{17}$ And here I extend this argument in a familiar way - if such idealized agents cannot know Fitch propositions, then we mere mortals cannot either.

These results can be extended in several dimensions. First, I note that in nonGettier G-cases where $\mathrm{G}$ does not believe $\mathrm{H} \wedge \mathrm{L}$, that conjunction will entail that $\mathrm{G}$

\footnotetext{
${ }^{17}$ Since we rely on necessitated versions of principles such as Anti-Akrasia in these proofs, what really follows is that no necessarily metaphysically omniscient and necessarily perfectly rational agent is able to know a Fitch proposition. This does not seem to me to diminish at all the strength of the inference to our inability to know such propositions, since all we have done is idealized these agents to be even more godlike. In what follows I leave implicit the clarification made here, but it applies throughout.
} 
The Poss-Ability Principle, G-cases, and Fitch Propositions

does not believe $\mathrm{H} \wedge \mathrm{L}$. Therefore, by another argument relying on closure over entailment and conjunction, idealized $\mathrm{G}+$ is able to know $\mathrm{H} \wedge \mathrm{L}$ in non-Gettier Gcases only if $\mathrm{G}+$ is able to know $(\mathrm{H} \wedge \mathrm{L}) \wedge \neg \mathrm{B}_{+}(\mathrm{H} \wedge \mathrm{L})$. By a structurally identical proof as above, we can show that this violates Believe-Ability whilst relying on weaker assumptions. We trade out Anti-Akrasia for Consistent Introspection:

(1) $2\left(\mathrm{~B}_{\mathrm{G}}\left(\Phi \wedge \neg \mathrm{B}_{\mathrm{G}} \Phi\right) \rightarrow\left(\mathrm{B}_{\mathrm{G}} \Phi \wedge \mathrm{B}_{\mathrm{G}} \neg \mathrm{B}_{\mathrm{G}} \Phi\right)\right) \quad$ (BG distribution over conjunction)

(2) $? \neg\left(\mathrm{B}_{\mathrm{G}} \Phi \wedge \mathrm{B}_{\mathrm{G}} \neg \mathrm{B}_{\mathrm{G}} \Phi\right) \quad$ (CI, PL, K axiom)

(3) ? $\neg\left(\mathrm{B}_{\mathrm{G}}\left(\Phi \wedge \neg \mathrm{B}_{\mathrm{G}} \Phi\right)\right) \quad(1,2, \mathrm{PL}, \mathrm{K}$ axiom $)$

(4) $\neg \diamond \neg \neg\left(\mathrm{B}_{\mathrm{G}}\left(\Phi \wedge \neg \mathrm{B}_{\mathrm{G}} \Phi\right)\right) \quad$ (3, Duality of $\left.\square\right)$

(5) $\neg \diamond\left(\mathrm{B}_{\mathrm{G}}\left(\Phi \wedge \neg \mathrm{B}_{\mathrm{G}} \Phi\right)\right)$

$(4, \mathrm{PL})$

(6) $\mathrm{A}_{\mathrm{G}} \mathrm{K}_{\mathrm{G}}\left(\Phi \wedge \neg \mathrm{B}_{\mathrm{G}} \Phi\right) \rightarrow \diamond \mathrm{B}_{\mathrm{G}}\left(\Phi \wedge \neg \mathrm{B}_{\mathrm{G}} \Phi\right) \quad$ (Believe-Ability)

(7) $\neg \mathrm{A}_{\mathrm{G}} \mathrm{K}_{\mathrm{G}}\left(\Phi \wedge \neg \mathrm{B}_{\mathrm{G}} \Phi\right)$

$(5,6, \mathrm{PL})$

Since Consistent Introspection is guaranteed simply from having perfect access to one's epistemic states, the above shows no metaphysically omniscient agent $\mathrm{G}$ with perfect introspection can know a proposition of the form $\Phi \wedge \neg \mathrm{B}_{\mathrm{G}} \Phi$. But nonGettier G-cases require this ability.

Second, it can actually be shown that G-cases are more generally in tension with Believe-Ability. The following principle follows by metaphysical omniscience:

Belief Follows Entailment: $?(\Phi \rightarrow \Psi) \rightarrow ?\left(\mathrm{~B}_{\mathrm{G}} \Phi \rightarrow \mathrm{B}_{\mathrm{G}} \Psi\right)$.

This fact may be exploited to show that the conjunction of Believe-Ability and AntiAkrasia rules out all G-cases, and the conjunction of Believe-Ability and Consistent Introspection rules out all non-Gettier G-cases.

As we have already noted, in all G-cases, $\mathrm{H} \wedge \mathrm{L}$ entails that $\neg \mathrm{K}_{\mathrm{G}}(\mathrm{H} \wedge \mathrm{L})$. Given this, we show that no agent $G$ satisfying Belief Follows Entailment and Anti-Akrasia can know $\mathrm{H} \wedge \mathrm{L}$, since $\mathrm{G}$ believing $\mathrm{H} \wedge \mathrm{L}$ would also require $\mathrm{G}$ believing that $\mathrm{G}$ does not know $\mathrm{H} \wedge \mathrm{L}$ :

$(1)$ 回 $\left(\mathrm{H} \wedge \mathrm{L} \rightarrow \neg \mathrm{K}_{\mathrm{G}}(\mathrm{H} \wedge \mathrm{L})\right)$

$(\mathrm{H} \wedge \mathrm{L}$ entailment $)$

(2) $\mathrm{g}\left(\mathrm{B}_{\mathrm{G}}(\mathrm{H} \wedge \mathrm{L}) \rightarrow \mathrm{BG}_{\mathrm{G}} \neg \mathrm{K}_{\mathrm{G}}(\mathrm{H} \wedge \mathrm{L})\right)$

(1, Belief Follows Entailment)

(3) $0\left(\mathrm{~B}_{\mathrm{G}} \neg \mathrm{K}_{\mathrm{G}}(\mathrm{H} \wedge \mathrm{L}) \rightarrow \neg \mathrm{B}_{\mathrm{G}}(\mathrm{H} \wedge \mathrm{L})\right)$

(Anti-Akrasia)

(4) $\triangle\left(\mathrm{BG}_{\mathrm{G}}(\mathrm{H} \wedge \mathrm{L}) \rightarrow \neg \mathrm{B}_{\mathrm{G}}(\mathrm{H} \wedge \mathrm{L})\right)$

(2, 3, PL, K axiom)

(5) $\square\left(\neg\left(\mathrm{BG}_{\mathrm{G}}(\mathrm{H} \wedge \mathrm{L}) \wedge \neg \neg \mathrm{BG}_{\mathrm{G}}(\mathrm{H} \wedge \mathrm{L})\right)\right)$

(4, PL, K axiom)

(6) $\mathrm{g}(\neg \mathrm{BG}(\mathrm{H} \wedge \mathrm{L}))$

(5, PL, K axiom)

(7) $\neg \diamond \neg \neg \mathrm{B}_{\mathrm{G}}(\mathrm{H} \wedge \mathrm{L})$

(6, Duality of 回) 
Noah Gordon
(8) $\neg \diamond \mathrm{BG}_{\mathrm{G}}(\mathrm{H} \wedge \mathrm{L})$
(7, PL)
(9) $\mathrm{AGK}_{\mathrm{G}}(\mathrm{H} \wedge \mathrm{L}) \rightarrow \diamond \mathrm{B}_{\mathrm{G}}(\mathrm{H} \wedge \mathrm{L})$
(Believe-Ability)
(10) $\neg \mathrm{AG}_{\mathrm{G}}(\mathrm{H} \wedge \mathrm{L})$
$(8,9, \mathrm{PL})$

Plausibly, a metaphysically omniscient, perfectly rational agent would satisfy the principles relied on above. Therefore no such agent is able to know $\mathrm{H} \wedge \mathrm{L}$. Again, I conclude from this that no lesser agent can either.

Finally, in any non-Gettier G-case $H \wedge \mathrm{L}$ entails that $\neg \mathrm{B}_{\mathrm{G}}(\mathrm{H} \wedge \mathrm{L})$. This means that the above argument can be run against any non-Gettier $\mathrm{G}$-case again trading Anti-Akrasia for Consistent Introspection, since $G$ believing $H \wedge L$ would then require $G$ believing that $G$ does not believe $H \wedge L$ (the proofs are identical in steps 4-10):
(1) $?\left(\mathrm{H} \wedge \mathrm{L} \rightarrow \neg \mathrm{B}_{\mathrm{G}}(\mathrm{H} \wedge \mathrm{L})\right)$
$(\mathrm{H} \wedge \mathrm{L}$ entailment $)$
(2) $?\left(\mathrm{~B}_{\mathrm{G}}(\mathrm{H} \wedge \mathrm{L}) \rightarrow \mathrm{B}_{\mathrm{G}} \neg \mathrm{B}_{\mathrm{G}}(\mathrm{H} \wedge \mathrm{L})\right)$
(1, Belief Follows Entailment)
(3) $?\left(\mathrm{~B}_{\mathrm{G}} \neg \mathrm{B}_{\mathrm{G}}(\mathrm{H} \wedge \mathrm{L}) \rightarrow \neg \mathrm{B}_{\mathrm{G}}(\mathrm{H} \wedge \mathrm{L})\right)$
(Consistent Introspection)
(4) $2\left(\mathrm{BG}_{\mathrm{G}}(\mathrm{H} \wedge \mathrm{L}) \rightarrow \neg \mathrm{B}_{\mathrm{G}}(\mathrm{H} \wedge \mathrm{L})\right)$
(2, 3, PL, K axiom)
(5) ? $\left(\neg\left(\mathrm{BG}_{\mathrm{G}}(\mathrm{H} \wedge \mathrm{L}) \wedge \neg \neg \mathrm{B}_{\mathrm{G}}(\mathrm{H} \wedge \mathrm{L})\right)\right)$
(4, PL, K axiom)
(6) ?ㄱ $\left(\neg \mathrm{B}_{\mathrm{G}}(\mathrm{H} \wedge \mathrm{L})\right)$
(5, PL, K axiom)
(7) $\neg \diamond \neg \neg \mathrm{B}_{\mathrm{G}}(\mathrm{H} \wedge \mathrm{L})$
(6, Duality of ?)
(8) $\neg \diamond \mathrm{BG}_{\mathrm{G}}(\mathrm{H} \wedge \mathrm{L})$
(9) $\mathrm{AG}_{\mathrm{G}}(\mathrm{H} \wedge \mathrm{L}) \rightarrow \diamond \mathrm{B}_{\mathrm{G}}(\mathrm{H} \wedge \mathrm{L})$
(Believe-Ability)
(10) $\neg \mathrm{AGK}_{\mathrm{G}}(\mathrm{H} \wedge \mathrm{L})$
$(8,9, \mathrm{PL})$

I reiterate that an agent with total introspective access satisfies Consistent Introspection. So no metaphysically omniscient, perfectly introspective agent can know $\mathrm{H} \wedge \mathrm{L}$ in any non-Gettier G-case.

It is worth noting that even if you disagree with some of my assessments about what principles certain idealized agents satisfy, the broader point is that these results show that if Believe-Ability holds, then any agent who did satisfy these constraints could not know a Fitch proposition or $\mathrm{H} \wedge \mathrm{L}$. And it seems dubious to hold that someone is able to know $\mathrm{H} \wedge \mathrm{L}$ only by failing to satisfy some of these constraints.

To summarize, I argued that agents satisfying certain closure principles on knowability are able to know $\mathrm{H} \wedge \mathrm{L}$ only if they are able to know a Fitch proposition. Contra Spencer, if one thinks, as seems intuitive, that Fitch propositions are unknowable, one should conclude not only that such agents are unable to know $\mathrm{H}$ $\wedge \mathrm{L}$, but that even lesser agents who do not satisfy these conditions are unable to 
The Poss-Ability Principle, G-cases, and Fitch Propositions

know $\mathrm{H} \wedge \mathrm{L}$, since one surely cannot know a proposition simply because of ignorance of its consequences. I then gave an independent argument for the unknowability of Fitch propositions based on Believe-Ability, a principle even weaker than PossAbility. Finally, I pointed out that Believe-Ability rules out the G-cases even independently of the argument about Fitch propositions. Therefore, both the unknowability of Fitch propositions and Believe-Ability are good reasons to reject Spencer's counterexamples to Poss-Ability. ${ }^{18}$

${ }_{18}$ Thanks to Gabriel Uzquiano, Giang Le, Kadri Vihvelin, John Hawthorne, and especially Jeff Russell for helpful comments. 